\title{
The Ethical Mutual Fund Performance Debate: New Evidence from Canada
}

Rob Bauer
Jeroen Derwall
Rogér Otten

\begin{abstract}
Although the academic interest in ethical mutual fund performance has developed steadily, the evidence to date is mainly sample-specific. To tackle this critique, new research should extend to unexplored countries. Using this as a motivation, we examine the performance and risk sensitivities of Canadian ethical mutual funds vis-à-vis their conventional peers. In order to overcome the methodological deficiencies most prior papers suffered from, we use performance measurement approaches in the spirit of Carhart (1997, Journal of Finance 52(1): 57-82) and Ferson and Schadt (1996, Journal of Finance 51(2): 425-461). In doing so, we
\end{abstract}

Rob Bauer is a Professor of Finance (chair: Institutional Investors) at Maastricht University in the Netherlands, an advisor to the board of ABP Investments, and co-founder of the European Centre for Corporate Engagement (ECCE). In addition, he is a senior researcher of Netspar and board member of the International Centre for Pension Management at the Rotman Business School in Toronto. His present research focus is on socially responsible investments, corporate governance, asset liability management, risk budgeting, and stock selection. His SRI research has been awarded the Moskowitz Prize (in 2002 and 2005) and the 2005 European Finance \& Sustainability Research Award.

Jeroen Derwall is an assistant professor of Finance at RSM Erasmus University and at Maastricht University, and co-manager of the European Centre for Corporate Engagement (ECCE). He has research experience in the areas of socially responsible investing, corporate social responsibility, equity and fixed-income portfolio management, and mutual funds. His PhD research focused on the economic consequences of corporate social responsibility and SRI policies. His work on socially responsible investing has been published in widely read international journals, and has been awarded the 2005 Moskowitz Prize and the 2005 European Finance \& Sustainability Research Award.

Rogér Otten is an Assistant Professor of Finance at Maastricht University in the Netherlands. His research is primarily in the areas socially responsible investing (SRI), corporate governance and mutual funds. His work on SRI funds has been awarded the 2002 Moskowitz Prize. investigate the aggregated performance and investment style of ethical and conventional mutual funds and allow for time variation in the funds' systematic risk. Our Canadian evidence supports the conjecture that any performance differential between ethical mutual funds and their conventional peers is statistically insignificant.

KEY WORDS: ethical mutual funds, mutual fund performance, performance measurement, socially responsible investing (SRI), business ethics

JEL CLASSIFICATION: G12, G20, G23, M14

\section{Introduction}

The number of mutual funds investing in companies that meet a variety of ethical criteria, better known as ethical mutual funds or socially responsible mutual funds, is growing rapidly worldwide. Although the principles of socially responsible investing (SRI) have been known for many decades, the need for ethical screening of corporate behavior has become exceptionally fashionable since the recent reports of some serious corporate environmental and accounting scandals. In fact, the strongly growing interest in the incorporation of social, moral, environmental or any other ethical criteria into the stock selection process may eventually affect corporate behavior as companies may become out of favour within the investment community when behaving unethically.

For quite some time, however, it has been argued that imposing ethical constraints on the equity investment process will come at the cost of inferior portfolio performance. Several oft-cited theories lie at the core of this prediction. First, because an ethical 
investment opportunity set is by construction a subset of the entire security investment universe, ethical investors forgo some benefits to diversification. Second, developing ethical investment screens and corporate social responsibility rankings can be an expensive practice that may ultimately factor into net return. Third, it has been suggested that irresponsible activities are more lucrative and recession-proof than responsible investments. ${ }^{1}$ Supporters of these views therefore claim that ethical mutual funds are likely to underperform their conventional peers.

In spite of these plausible opinions, prior related literature has not been able to find a substantial performance gap between ethical and mainstream portfolios. Initially, ethical fund studies primarily focused on traditional performance methods, such as the Sharpe or Jensen measure, to compare ethical mutual funds to either conventional mutual funds or an ethical or standard index. Along these lines, the majority of research provided empirical evidence from the United States, United Kingdom and Australia. ${ }^{2}$ However, while the growing body of studies may seem impressive at first glance, the evidence to date could be sample-specific. To tackle this critique, the analysis should be carried over to other countries.

The objective of this study is twofold. First, with the intention to provide significant complementary evidence on ethical mutual fund performance, we examine the Canadian ethical fund market. Although being the second-largest retail market in the world (Social Investment Organization, 2000), the Canadian ethical mutual fund industry has attracted little attention in the literature. To the best of our knowledge, Asmundson and Foerster (2001) is the only published study that explored this area. They examined the performance of Canadian ethical mutual funds with domestic equity orientation vis-àvis the performance of the TSE 300 Index and found no statistically meaningful differences in return but some weak evidence suggesting that ethical investing is less risky. However, their results are somewhat sensitive to their assumption of what represents an average conventional mutual fund, since they do not compare ethical mutual funds with conventional mutual funds directly.

The second purpose of the paper is to address potential benchmark problems when evaluating the relative performance of ethical mutual funds in Canada. Asmundson and Foerster (2001) calculate risk-adjusted returns by comparing fund performance to a broad Canadian equity benchmark, the TSE300. Their approach builds on a 1-factor framework, in which returns on actively managed funds can be explained by only one passive market index, where a fund's sensitivity to that index measures the fund's systematic risk, plus a return component independent of risk that captures the contribution of the fund manager. This framework has been under strenuous attacks in recent literatures, which suggest that singleindex specifications cannot fully explain the returnrisk characteristics of equity investment portfolios. For example, the single-index model does not account for risk associated with non-index holdings, such as small cap stocks. In addition, several celebrated articles by Fama and French (1992, 1993, 1996) call for a risk factor that explains the anomalously large return spread between stocks with high book-price ratios ("value" stocks) and those with low book-price ratios ("growth" stocks). Fama and French (1993) propose a multifactor model that includes (i) a value-weighted market proxy, (ii) a factor capturing the risk premium associated with smallversus-large company stocks, and (iii) a variable that accounts for the "value"-versus-"growth" stock premium. Carhart (1997) augments the three-factor model by a momentum strategy that buys last year's return winners and sells short past losers. We argue that not using a multifactor model to evaluate ethical funds can lead to an erroneous assessment of mutual fund performance. Without multifactor models, we cannot separate returns associated with social investment policies from the returns on common investment styles that do not incorporate those policies. Bauer et al. (2005) recently re-examined the performance of ethical mutual funds in the United States, the United Kingdom and Germany using multifactor models that control for size, book-tomarket and momentum bias in equity portfolios. Their evidence not only suggests that ethical funds perform similar to conventional mutual funds, but also indicate that multiple style factors are important in explaining ethical mutual fund performance. Therefore, we follow Bauer et al. (2005, hereafter $\mathrm{BKO}$ ) and evaluate ethical mutual fund performance and investment style relative to conventional funds using Carhart's (1997) 4-factor model.

The remainder of this paper is organized as follows: the next section gives an overview of the 
Canadian retail market for ethical investments and an outline of the data set. In Section "Empirical results" we discuss the empirical analysis and the results. Finally, Section "Concluding remarks" provides a summary and conclusion.

\section{Data}

\section{General market overview}

In December 2000 the Social Investment Organization (SIO), Canada's leading non-profit organization dedicated to the progression of socially responsible investing, released its first results of an extensive survey on the condition of ethical investing in Canada. Key findings of this report showed that the total amount of assets in ethical investments in Canada equalled approximately $\$ 50$ billion at the end of the previous millennium, about $3 \%$ of the industry as a whole. Moreover, according to SIO estimates the SRI-retail market grew at a higher than average rate of $75 \%$, from $\$ 5.9$ billion in 1998 to $\$ 10.35$ billion in 2000 . Although the total number of Canadian ethical equity mutual funds is still rather low relative to other countries, the estimates suggest that the Canadian SRI-retail industry is the second largest in the world (Social Investment Organization, 2000). ${ }^{3}$

\section{Mutual fund data}

Our mutual fund sample consists of Canadian ethical and conventional mutual funds with domestic equity orientation only. Hence, we exclude foreign, balanced and guaranteed funds. We furthermore ignore funds less than 12-months of age. The resulting data set comprises adjusted Net Asset Values on mutual funds that focus on long-term capital appreciation by investing primarily in Canadian stocks, although a small fraction may occasionally be invested in bonds, cash positions or non-domestic securities. All data are obtained from Globefund.com. Monthly logarithmic returns are calculated using funds' net asset values adjusted for distributions. ${ }^{4}$ All fund returns are net of expenses.

Unfortunately, our sample does not include data on disappearing mutual funds. We expect the impact of survivor bias on the empirical results to be rather asymmetrical. That is, survivor bias in the data set will probably not significantly affect the performance statistics on ethical funds because, as far as we know, no domestic ethical fund disappeared during the sample period. On the other hand, the absence of dead funds in the sample is likely to bias conventional mutual fund performance in this study upwards. ${ }^{5}$ Whenever necessary, the potential effects of survivorship bias will be taken into consideration.

Table I reports summary statistics of an equally weighted portfolio of all ethical mutual funds in the sample and those of an equally weighted conventional fund portfolio. In addition, we present annualized performance data on the S\&P/TSX Composite Index. As a first indication of risk-adjusted performance, we present the Sharpe ratio. This ratio divides the average excess fund return over the sample period by the standard deviation of returns over that period. The numerator is the return earned by the fund relative to the return on an investment in a risk-free asset. The denominator penalizes the achieved excess return for associated volatility. Therefore, the ratio measures the return to risk trade-off, where a higher Sharpe ratio is better.

Over the entire sample period, the average ethical fund earned a lower average annualized return than its conventional counterpart: $5.12 \%$ versus $5.48 \%$. Corresponding standard deviations $(14.21 \%$ and $14.05 \%)$ suggest that ethical funds were also more risky. Unsurprisingly, the Sharpe ratios suggest that conventional funds outperformed ethical funds on a return-to-risk basis. The average return on the S\&P/ TSX Composite was higher for this particular sample period (6.40\%) compared to the average ethical and conventional fund return, but the return variability was substantially higher as well $(17.49 \%)$. The corresponding Sharpe ratio suggests that the index outperformed ethical funds as well as conventional funds. Furthermore, a comparison of the expense ratios presented in the table reveals that ethical mutual funds charge some additional compensation.

\section{Factor benchmarks}

The regression approaches we employ to assess fund performance required us to collect various data. In order to estimate multifactor models in the spirit of Carhart (1997), we construct factor portfolios using all Canadian stocks in the Worldscope database. The 


\section{TABLE I}

Summary statistics on Canadian mutual funds

\begin{tabular}{lccccc}
\hline Fund & Return & St.Dev. & Sharpe & Exp.ratio & \#Funds \\
\hline Ethical portfolio & $5.12 \%$ & $14.21 \%$ & 0.05 & $2.71 \%$ & 8 \\
Conventional portfolio & $5.48 \%$ & $14.05 \%$ & 0.08 & $2.41 \%$ & 267 \\
S\&P/TSX composite & $6.40 \%$ & $17.49 \%$ & 0.12 & &
\end{tabular}

This table reports summary statistics on ethical and conventional mutual funds in the sample and on the S\&P/TSX Composite Index. Ethical and conventional fund returns are calculated based on an equally weighted portfolio of all funds. Mean return, corresponding standard deviation and Sharpe ratio are presented on an annualized basis. The Sharpe ratio is defined as the ratio of the excess return on the fund portfolio or index to the standard deviation of return.Sample period: 1994:01-2003:01.

main benefit of the Worldscope stock universe is that it covers over $98 \%$ of total market capitalization. To calculate the first determinant in the multifactor model, the excess market return, we deduct the monthly T-Bill rate from the monthly return on the value-weighted market proxy. We use the Canadian 30-day T-bill rate as a measure of the risk-free rate. End-of-month T-Bill rates are from the Bank of Canada. The second determinant is the return spread between a small cap portfolio and a large cap portfolio. The small cap portfolio covers the bottom $20 \%$ of total market capitalization after ranking all stock according to size. The remaining part is assigned to the large cap portfolio. The third regressor is the difference in return between a value stock portfolio and a growth stock portfolio. Following Fama and French (1993), we first rank all stocks according to their book-tomarket ratio and then assign the top $30 \%$ of market capitalization to the high book-to-market (i.e. value) portfolio and the bottom 30\% to the low book-tomarket (i.e. growth) portfolio. Finally, we consider a momentum factor which is defined as the monthly return spread between a past 12-month winner portfolio and a past 12-month loser portfolio. After having ranked all stocks on their prior 12-month return, we classify the top 30\% as "winners" and the bottom 30\% as "losers". All factor portfolios are rebalanced annually at the end of each year.

We additionally consider the explanatory power of a leading Canadian ethical equity index, launched recently. The Jantzi Social Index is a value-weighted index consisting of 60 companies that pass a variety of social and environmental screens. ${ }^{6}$ Monthly returns on the index are provided by Michael Jantzi Research Associates Inc.
Traditionally, performance has been measured using unconditional expected returns under the assumption that investors make no use of information about the state of the economy to form expectations and to engage in dynamic trading strategies. However, if money managers trade on publicly available information, unconditional models that assume a time-invariant beta portray a biased picture of fund performance. For this reason, Ferson and Schadt (1996) advocate conditional performance measurement.

Our study follows Ferson and Schadt (1996) and uses a conditional performance evaluation approach that allows for time variation in funds' betas. For this purpose, we constructed various Canadian economic information variables. The variables are: (a) the 3-month Treasury-Bill rate, (b) the term spread, calculated as the long-term government bond rate minus the T-Bill rate, (c) the quality spread, defined as the yield spread between the long-term corporate bond and the long government bond, and (d) the dividend yield of the S\&P/TSX Composite Index.

\section{Empirical results}

Jensen's alpha

The most widely employed benchmark model in mutual fund performance studies is the CAPMbased single-factor model. In this scenario, a fund's outperformance, known as Jensen's alpha, is measured as the difference between the return on the mutual fund and the return on the single-factor benchmark according to an estimated CAPM. 
Hence, when computing the Jensen measure, it is implicitly assumed that the single-index model is sufficiently capable of explaining the cross-section of stock returns.

In this section, we discuss the results of applying the single-factor regression on our data to estimate the Jensen measure. Formally, we estimate the following 1-factor model for both the ethical fund portfolio and its non-ethical counterpart:

$$
R_{i t}-R_{f t}=\alpha_{i}+\beta_{i}\left(R_{m}-R_{f t}\right)+\varepsilon_{i t},
$$

where, $R_{i t}$ is the return on mutual fund $i$ in month $t, R_{f t}$ the risk-free rate at $t$ measured by the 30-day T-Bill rate, $R_{m}$ the return on the market proxy in month $t, \varepsilon_{i t}$ an error term.

Consequently, $\beta_{i}$ (beta) measures the market risk exposure of the fund and $\alpha_{i}$ represents Jensen's alpha. The market proxy is measured by a value-weighted market portfolio, constructed using the Worldscope database.

Empirical results are presented in Table II. For each coefficient, (we report the corresponding t-statistic) derived from Newey and West (1987) standard errors. As the primary focus of our research is the performance and style differential between ethical mutual funds and their conventional counterparts, we also investigate the returns on a 'difference' portfolio, which is constructed by subtracting the conventional mutual funds returns from the return on the ethical mutual fund portfolio.
Regression results show that both ethical mutual funds and their conventional peers underperform the value-weighted market proxy. The observed alphas $(-2.93 \%$ and $-2.56 \%$, respectively) are statistically significant at the $10 \%$ level. The performance results for the 'difference' portfolio show that neither alpha nor beta is statically significant. Hence, based on these outcomes we cannot reject the notion that no statistically significant difference exists in the performance of ethical funds and their conventional peers. ${ }^{7}$

Since the investment universe of ethical mutual fund managers is determined by ethical screens, the single-factor regression of excess ethical fund returns on a standard equity index may lead to biased estimates of mutual fund performance. Therefore, it is useful to consider a relevant ethical equity index to measure the performance of ethical mutual funds. We repeat our computations but now using the return on the Jantzi Social Index as the determinant in the single-factor model. Although the Jantzi Social Index was introduced only recently, its performance has been back-tested for the period 1995-1999. Consequently, we are only able to estimate Jensen's alpha using monthly ethical index returns for the period January 1995-January 2003. For comparison purposes, we also run a similar single-index regression using 8-year data on the Worldscope market proxy.

Regression results are provided in Table III. With regard to the ethical fund portfolio, the estimated alpha is negative and not statistically significant at the

TABLE II

Empirical results 1-factor regressions

\begin{tabular}{|c|c|c|c|c|}
\hline \multicolumn{2}{|l|}{ Fund } & $\alpha$ & $\beta$ & Adj. $R^{2}$ \\
\hline Ethical portfolio & & $-2.93(-1.74)^{\star}$ & $0.84(35.56) \dagger$ & 0.91 \\
\hline Conventional portfolio & & $-2.56(-1.67)^{\star}$ & $0.84(-23.31) \dagger$ & 0.92 \\
\hline & Difference & $-0.37(-0.31)$ & $0.00(-0.07)$ & -0.01 \\
\hline
\end{tabular}

This table reports the results from CAPM-based regressions. To measure ethical and conventional mutual fund performance, we estimated the model formally defined by Equation (1): $R_{i t}-R_{f t}=\alpha_{i}+\beta_{i}\left(R_{m}-R_{f t}\right)+\varepsilon_{i t}$, (1) where $R_{i t}-R_{f t}$ denotes the local return on a fund portfolio in excess of the risk-free rate and $R_{m}-R_{f t}$ is the excess return on the market portfolio constructed using the Worldscope database. The "difference" portfolio is constructed by subtracting conventional mutual fund returns from the returns on the ethical mutual fund portfolio. T-statistics (in brackets) are derived from Newey-West heteroskedasticity and autocorrelation consistent standard errors. Sample period: 1994:01-2003:01.

$\star^{\star}$ Coefficient is statistically significant at $10 \%$ level.

$\dagger$ Coefficient is statistically significant at $1 \%$ level. 
TABLE III

Empirical results 1-factor regression using ethical equity index

\begin{tabular}{|c|c|c|c|c|c|c|c|}
\hline \multirow{2}{*}{\multicolumn{2}{|c|}{ Fund }} & \multicolumn{3}{|c|}{ Worldscope market proxy } & \multicolumn{3}{|c|}{ Jantzi social index } \\
\hline & & $\alpha$ & $\beta$ & Adj. $R^{2}$ & $\alpha$ & $\beta$ & Adj. $R^{2}$ \\
\hline \multirow{3}{*}{$\begin{array}{l}\text { Ethical portfolio } \\
\text { Conventional portfolio }\end{array}$} & & $-2.44(-1.35)$ & $0.84(32.59)^{\dagger}$ & 0.90 & $-0.58(-0.24)$ & $0.68(10.31)^{\dagger}$ & 0.74 \\
\hline & & $-2.18(-1.27)$ & $0.84(21.55)^{\dagger}$ & 0.92 & $-0.30(-0.11)$ & $0.67(7.82)^{\dagger}$ & 0.75 \\
\hline & Difference & $-0.27(-0.21)$ & $0.00(0.02)$ & -0.01 & $-0.28(-0.23)$ & $0.01(0.20)$ & -0.01 \\
\hline
\end{tabular}

This table reports the results from CAPM-based regressions to estimate mutual fund performance using a conventional value-weighted market proxy based on the Worldscope stock universe, and the Jantzi Social Index. Columns 2, 3 and 4 display results from a single-factor regression of excess aggregate fund returns on the excess return on the value-weighted market proxy. Columns 5, 6 and 7 display results from similar single-factor regressions using the Jantzi social index serving as an alternative market proxy. The "difference" portfolio is constructed by subtracting conventional mutual fund returns from the returns on the ethical mutual fund portfolio. All alphas are annualized. T-statistics (in brackets) are derived from Newey-West heteroskedasticity and autocorrelation consistent standard errors. Sample period: 1995:01-2003:01.

$\dagger$ Coefficient is statistically significant at $1 \%$ level.

usual cut-off levels. The results therefore point out that ethical mutual funds are not able to outperform their ethical index. Striking is that the adjusted $R^{2}$ from the model with the ethical index is lower (0.74) than the $R^{2}$ from the standard single-index model (0.90), indicating that the ethical index is less capable of explaining ethical mutual fund performance than a standard equity index. Equally remarkable are the fund betas, which reveal that the ethical fund portfolio is more exposed to a standard market index $(\beta=0.84)$ than to the ethical index $(\beta=0.68)$. It is questionable whether these findings can be fully explained by the fact that the ethical index comprises only 60 stocks, whereas the conventional index represents a much larger stock universe. The results are in line with BKO (2005), who examined the explanatory power of domestic ethical indexes in the United Kingdom and the United States. Provided the ethical index sufficiently represents an ethical stock portfolio, our findings raise concern over whether Canadian ethical funds are truly distinguishing themselves by investing in ethical securities only. Similar observations are put forward by Haigh and Hazelton (2004) in their investigation of Australian ethical mutual funds. They even go as far as suggesting: "The distinction between SRI funds and conventional funds may be largely in name".

Recently the traditional performance measurement routines discussed thus far have been criticized for providing biased estimates of mutual fund performance. There is substantial evidence showing that if funds are considerably involved in style investment strategies (e.g. small caps or value strategies), their returns cannot be fully explained by the single-factor model. We therefore expect to shed more light on ethical fund performance and investment behaviour throughout the remainder of this paper by means of enhanced performance analyses in a multivariate setting.

\section{Multifactor models}

It has been repeatedly argued that the 1-factor asset pricing model is insufficiently able to explain the cross-section of expected stock returns. Fama and French (1993) demonstrated that the CAPM is inefficient and introduced a 3-factor model that includes the factors SMB and HML in addition to the excess market return. In their study SMB corresponds to the return difference between a small and a large stock portfolio and HML represents the return difference between a value stock portfolio and a growth stock portfolio using the book-to-market ratio as a discriminating factor. Fama and French's findings imply that the 3 -factor model will be incrementally useful in explaining mutual fund returns if fund managers significantly engage in style investment strategies.

While the benefits of the 3-factor model are nowadays acknowledged, the model is subject to further improvement. In response to evidence 
showing that the 3-factor model is insufficiently capable of explaining the Jegadeesh and Titman (1993)-momentum strategy, Carhart (1997) suggested the addition of a momentum factor to existing models to capture persistence in fund performance. The resulting 4-factor model is expected to provide reliable information on a fund's relative performance and allows us to further estimate to what degree a fund engages in various accepted equity investment strategies. Recent studies by Berkowitz and Qiu (2001; 3-factor model) and by L'Her et al. (2001; 4-factor model) confirm the notion that multifactor models are able to explain the cross-sectional variation in Canadian equity returns.

In addition to this, there now is evidence confirming that ethical mutual fund performance is indeed attributable to style tilts, which cannot be accounted for in a single-index environment. For example, Gregory et al. (1997) found that the small firm effect is significant in explaining U.K. ethical trust performance. BKO (2005) found evidence suggesting that ethical mutual funds are less exposed to the market portfolio compared to conventional funds, but more small cap- and growth stock-oriented. Estimates of a mutual fund's factor loadings and alpha are therefore likely to be more reliable in a multivariate framework.

Although most funds in our sample primarily invest in the Canadian equity market, some occasional exposure to foreign markets may be allowed up to pre-specified limits. For that reason, we additionally measure fund performance by means of the domestic 4-factor model described earlier augmented by a U.S. market index.

Using the average ethical and conventional mutual fund data for further analysis, we estimate the following equations:

$$
\begin{aligned}
R_{i t}-R_{f t}= & \alpha_{i}+\beta_{0 i}\left(R_{m}-R_{f t}\right)+\beta_{1 i} \mathrm{SMB}_{t} \\
& +\beta_{2 i} \mathrm{HML}_{t}+\beta_{3 i} \mathrm{MOM}_{t}+\varepsilon_{i t},
\end{aligned}
$$

and

$$
\begin{aligned}
R_{i t}-R_{f t}= & \alpha_{i}+\beta_{0 i}\left(R_{m}-R_{f t}\right)+\beta_{1 i} \mathrm{SMB}_{t}+ \\
& \beta_{2 i} \mathrm{HML}_{t}+\beta_{3 i} \mathrm{MOM}_{t}+\beta 4_{i} \mathrm{US}_{t}+\varepsilon_{i t}
\end{aligned}
$$

where, $\mathrm{SMB}_{t}$ is the return difference between a small cap portfolio and a large cap portfolio in month $t, \mathrm{HML}_{t}$ the return difference between a value (high $\mathrm{B} / \mathrm{M}$ ) portfolio and a growth (low B/ M) portfolio in month $t, \mathrm{MOM}_{t}$ the return difference between a portfolio of past 12-month winners and a portfolio of past 12-month losers in month $t, \mathrm{US}_{t}$ the excess Canadian dollar return on the S\&P500 index at $t$.

Panel A and B in Table IV report the results from the estimation of the 4-factor model and 5-factor model respectively. In the multivariate framework the adjusted $R^{2}$ is higher than in the CAPM-environment, which indicates that the multifactor models are more capable of explaining aggregate mutual fund returns. The alphas presented in both panels provide evidence of strong and significant underperformance for ethical mutual funds $(\alpha=-3.18 \%)$ as well as for their conventional peers $(\alpha=-2.90 \%)$. The coefficients and t-statistics on the factors MKT and SMB imply that both ethical and conventional mutual funds are significantly exposed to the market factor and also significantly biased towards small capitalization stocks. Loadings on HML and MOM, however, are insignificant. Furthermore, empirical results in panel $\mathrm{B}$ show that the addition of the foreign component does not affect the alpha estimates substantially. However, it appears that a small but statistically significant portion of the exposure to MKT is now captured by the U.S. factor.

The magnitude of the observed underperformance of Canadian mutual funds as a whole seems rather extreme at first glance. Our results are nonetheless similar to those reported by Berkowitz and Qiu (2003), who measured the performance of mutual funds managed by publicly traded companies relative to the performance of funds managed by private management companies. A potential source of the strong overall underperformance is the high expense ratio associated with the Canadian mutual fund industry. ${ }^{8}$

The performance evaluation results for the 'difference' portfolio point out that the performance gap between ethical and conventional mutual funds is statistically insignificant. While the absence of a performance difference is not surprising and consistent with the results of prior multifactor regression results, i.e. BKO (2005), our results are puzzling in the sense that none of the differences in factor loadings between ethical mutual funds and their 
Rob Bawer et al.

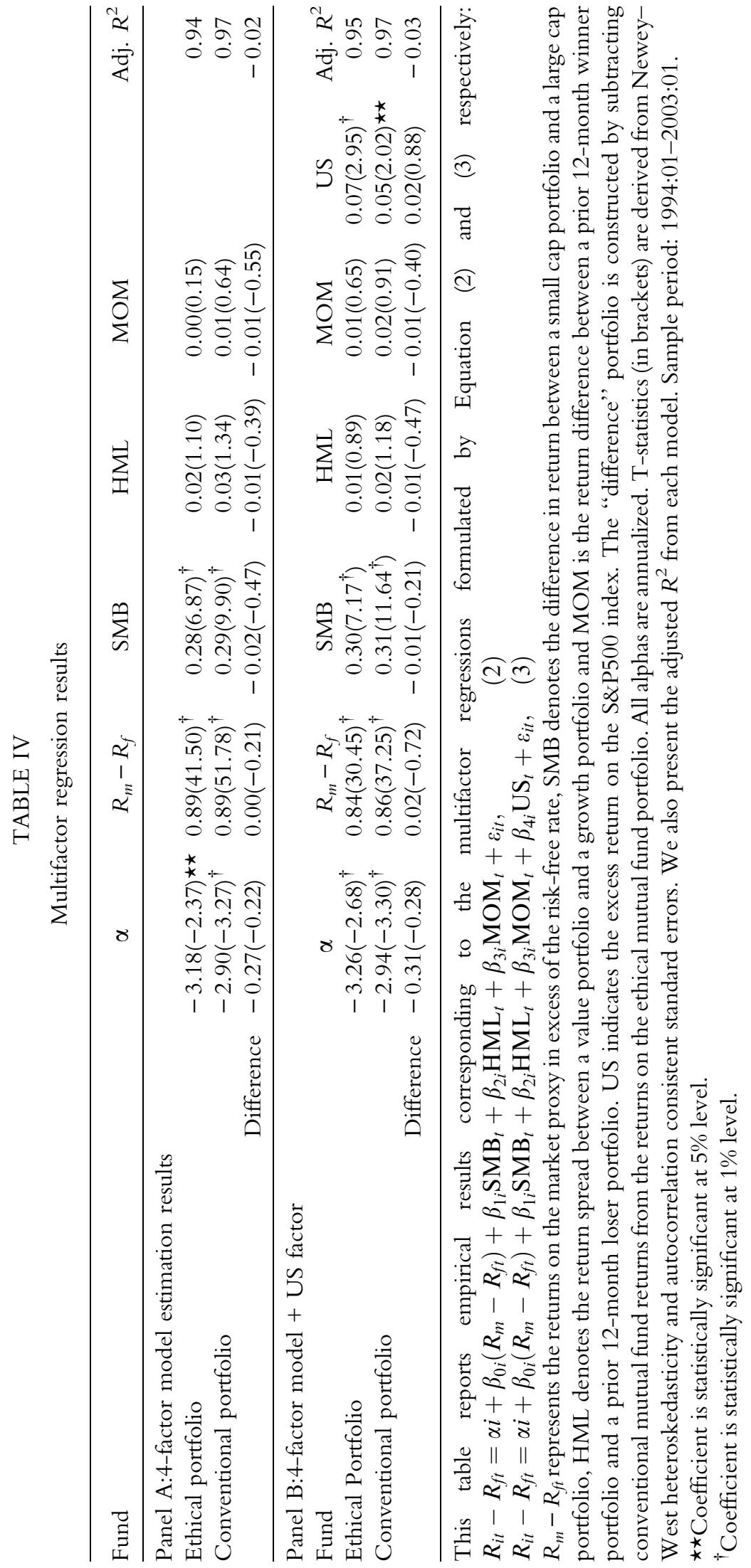


conventional peers is significant. Thus, at the aggregate level, it seems like Canadian ethical and conventional mutual funds exhibit virtually identical sensitivities.

This result can be explained along several lines. One potential source of this observation is the so called "best-of-sector" approach that is currently very popular in the ethical investment industry. The oldest generation of ethical funds primarily filtered out companies that operate in sectors considered controversial from an ethical perspective (e.g. alcohol, gambling, military equipment, nuclear energy and tobacco). Companies that violate environmental standards or certain human rights are usually excluded from the investment universe as well. It is therefore no surprise that ethical stocks may be sector-specific; see for example diBartolomeo and Kurtz (1999). As a result of this approach, known as negative screening, ethical portfolios may suffer from a lack of diversification. To reduce extreme sector tilts, many ethical investors now adopt so-called positive screening methods to identify firms that are "best-in-sector" improvers of their social or environmental performance. Yet, critics believe that improper use of best-of-sector analysis easily results into a portfolio that insufficiently represents social awareness. In other words, if ethical funds support investing in "the least controversial" companies from each sector rather than only in "good" ones, the distinction between ethical and conventional mutual funds could become too vague. However, testing such a hypothesis is beyond the scope of this paper.

A second possibility is that the outcomes for the "difference" portfolio are not robust to the choice of observation window. In order to investigate this possibility, we perform a sensitivity analysis with respect to the coefficient computations by estimating the coefficients in the four-factor model recursively. Figure 1 displays the time-variation in alpha and factor loading differences as well as corresponding 95\% confidence intervals.

Consistent with prior observations, the alpha for the "difference" portfolio remained insignificant throughout the entire expanding window analysis. Contrary to the results in Table IV, which suggested the absence of any difference in factor loadings between ethical and conventional funds, Figure 1 indicates that significant differences in loading on
HML and MOM existed up to the end of 2000. Thus, ethical funds were more value oriented than their conventional peers and exhibited a more positive loading on the momentum factor. As it appears, however, these differences in loading disappear quickly due to a "shock" in the data at the beginning of 2001. This shock is almost entirely attributable to one company in the data set, namely Nortel.

The boom and bust of the Nortel stock is well known. Through a large number of acquisitions during the nineties Nortel attempted to meet growing Internet demands. Prior to the burst of the technology bubble the company had grown tremendously, making the Nortel stocks jointly represent over $35 \%$ of the entire Canadian market. However, the collapse of the TMT market initiated a sharp decrease in Nortel's stock prices, causing an incredible decline in market value in less than 1 year.

Unsurprisingly, Nortel's impact on our factor portfolios is severe. At the end of June 2000, approximately $70 \%$ of our large cap portfolio and of the growth portfolio consisted of Nortel stocks. At the next rebalancing date Nortel's weight in the large stock and growth portfolio became $22 \%$ and $11 \%$, respectively. The impact on the momentum factor is even more dramatic. At the end of June 2000, Nortel's shares made up $73 \%$ of the winner portfolio's market value. One year later, the company's stocks disappeared into the loser segment.

It would be interesting to investigate the performance of ethical funds versus conventional funds after adjusting for Nortel's effects. We thus considered the addition of a "Nortel factor" to our multifactor performance models. The results of adding the excess return on Nortel stocks, not reported due to space limitations, were similar to previous outcomes. For all the portfolios under consideration, we did not observe a significant loading on the Nortel factor. Furthermore, the model adj. $R^{2}$ decreased as a result of adding the Nortel factor, suggesting that this regressor does not have any incremental explanatory power.

\section{Conditional performance evaluation}

In this section, we extend conventional multifactor modeling techniques and consider the conditional 

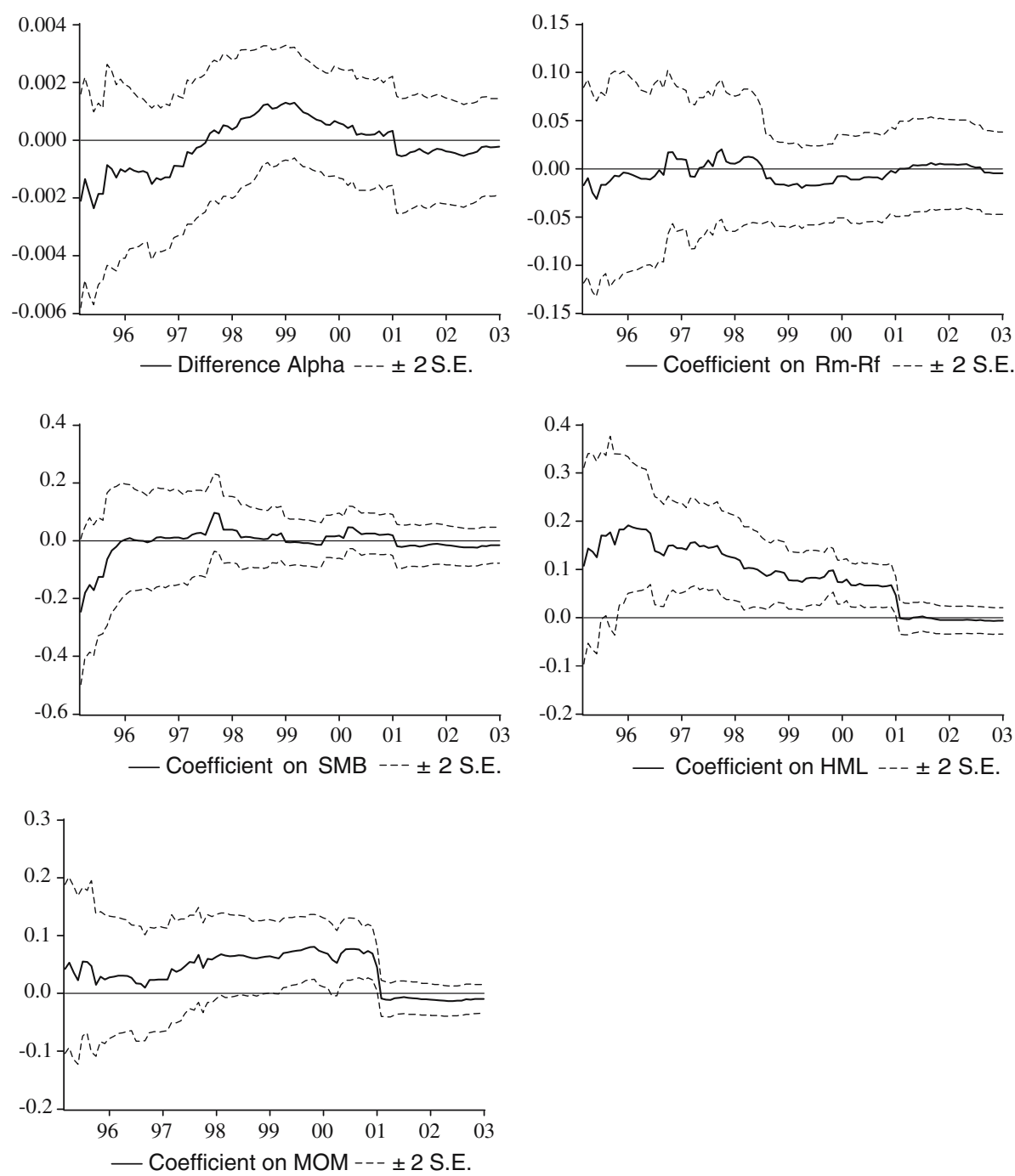

Figure 1. Recursive coefficient estimates: the 'difference' portfolio.

modeling approach suggested by Ferson and Schadt (1996) and Chen and Knez (1996) to assess ethical mutual fund performance. Unconditional factor models may deliver heavily biased performance measures if managers employ dynamic trading strategies, e.g., using publicly available information about the economy. Conditional modeling solves this problem by incorporating publicly available economic instruments into performance estimation to account for the possibility of time variation in betas and expected return.

Formally, the conditional single-index model is of the form:

$$
\begin{aligned}
R_{i t}-R_{f t}= & \alpha_{i}+\beta_{i 0}\left(R_{m t}-R_{f t}\right) \\
& +B_{i}^{\prime} Z_{t-1}\left(R_{m t}-R_{f t}\right)+\varepsilon_{i t},
\end{aligned}
$$

where, $Z_{t-1}=\mathrm{a}$ vector of lagged information variables. While Ferson and Schadt (1996) consider a conditional CAPM, their methodology is also applicable in a multivariate framework. In order to obtain the most accurate estimates of alpha, we condition all coefficients in the unconditional 4-factor model on a predetermined set of economic information variables. In other words, in addition to including the determinants in the unconditional model, we also include 
their interactions with a vector of lagged information variables. The end $t$ is a conditional 4-factor model that allows for time variation in factor loadings.

Largely following prior studies in the area of conditional performance evaluation, we incorporate the following information variables into the conditional multifactor regression procedure: (a) a lagged T-bill rate, (b) the lagged term spread defined as the yield spread between a long term government bond and the T-bill rate, (c) the lagged quality spread defined as the yield spread between a 10-year corporate bond and a 10-year government bond and (d) the lagged dividend yield of the S\&P/TSX Composite Index. A large body of literature has discussed the economic relevance of these instruments; see for example Chen et al. (1986) and Pesaran and Timermann (1995).

Regression results are reported in Table V. In order to compare the results from the unconditional model with those from the conditional model, we import some of the results presented in Table IV. Columns 2 and 3 display the alphas, t-statistics and adjusted $R^{2}$ values calculated in the previous section using the unconditional 4-factor model. Columns 4 and 5 show the estimation results from the conditional 4-factor model. Wald test results ( $p$-values) are presented in the last column to examine the incremental explanatory power of conditioning betas on a vector of lagged economic variables.

Wald test results show that in every case the hypothesis of time-invariant betas can be rejected at the 5\% level, confirming the importance of a framework that considers time variation in factor exposures. Furthermore, conditional performance measurement has provided a more optimistic judgment of ethical and conventional fund performance as the alphas $(-2.50 \%$ and $-2.11 \%)$ are slightly higher compared to the results from the unconditional approach $(-3.18 \%$ and $-2.90 \%)$. Nonetheless, the results pertaining to the difference portfolio suggest that any performance difference between ethical and non-ethical mutual funds is negligible from a statistical point of view, thereby confirming previous outcomes.

\section{Concluding remarks}

This study presents new evidence on the performance and investment style of ethical mutual

TABLE V

Unconditional versus conditional performance evaluation

\begin{tabular}{llllllll}
\hline & \multicolumn{2}{c}{ Unconditional model } & & \multicolumn{3}{c}{ Conditional model } \\
\cline { 7 - 8 } \cline { 7 - 8 } & & 4-Factor $\alpha$ & Adj. $\mathrm{R}^{2}$ & & 4-Factor $\alpha$ & Adj. $R^{2}$ & Wald (p-value) \\
\hline Ethical portfolio & $-3.18(-2.37)^{\star \star}$ & 0.94 & & $-2.50(-1.64)^{\star}$ & 0.94 & 0.015 \\
Conventional portfolio & & $-2.90(-3.27)^{\dagger}$ & 0.97 & & $-2.11(-2.04)^{\star \star}$ & 0.97 & 0.000 \\
& Difference & $-0.27(-0.22)$ & -0.03 & & $-0.39(-0.33)$ & 0.12 & 0.000
\end{tabular}

This table reports the results from unconditional (columns 2 and 3) and conditional (columns 4 and 5) multifactor regressions. Empirical results correspond to the conditional alternative to the unconditional 4-factor model formulated by Equation (2). In the conditional modeling framework, we allow the 4 factor exposures to vary over time as a function of (a) a lagged T-bill rate, (b) the lagged term spread, (c) the lagged quality spread and (d) the lagged dividend yield of the S\&P/TSX Composite Index. The "difference" portfolio is constructed by subtracting conventional mutual fund returns from the returns on the ethical mutual fund portfolio. All alphas are annualized. T-statistics (in brackets) are derived from Newey-West heteroskedasticity and autocorrelation consistent standard errors. We also present the adjusted $R^{2}$ from each model. Wald test results ( $p$-values) are presented to examine the incremental explanatory power of conditioning betas on a vector of lagged economic variables. Sample period: 1994:01-2003:01.

${ }^{\star}$ Coefficient is statistically significant at $10 \%$ level.

$\star \star$ Coefficient is statistically significant at $5 \%$ level.

${ }^{\dagger}$ Coefficient is statistically significant at $1 \%$ level. 
funds. Studying the Canadian market yields out-of sample evidence for a quickly growing retail market. Using a wide range of statistical models, we compare the risk-adjusted performance of Canadian ethical mutual funds relative to their conventional peers. While most previous work on ethical mutual fund performance has limited its attention to single-factor benchmark models, we utilize multifactor performance evaluation models. Multifactor specifications not only improve performance measurement but also enable us to investigate ethical mutual fund investment styles in greater detail.

Our empirical results are fourfold. First, using a single-factor model, we find no significant performance difference between ethical and conventional mutual funds. Second, we find that a single-factor model containing a standard market proxy has more explanatory power than an ethical equity index. This surprising result casts doubt on the distinctive ethical component of ethical mutual funds. Third, after applying a multifactor model that controls for returns associated with several common investment styles (i.e. based on size, book-to-market, and stock price momentum), we find no significant difference in performance between ethical mutual funds and their conventional peers. Fourth, on average, we find no evidence that the investment style exposures of ethical mutual funds differ significantly from those of conventional mutual funds.

The results of our study largely corroborate previous research on ethical mutual fund performance. Investing in ethical mutual funds does not lead to returns that are significantly different from those delivered by conventional mutual funds. Therefore, our study does not support the claim that imposing ethical constraints leads to weaker investment performance. The investment implications are clear: Canadian investors can allocate their money to ethical mutual funds without experiencing a financial penalty vis-à-vis conventional mutual funds.

However, the degree to which ethical mutual funds distinguish themselves from conventional funds is not very evident. Although ethical funds claim to screen in several ways, we cannot find significant differences in investment styles. Moreover, ethical fund returns correlate more with conventional market indices than with ethical indi- ces. These counterintuitive observations should be of interest to regulators who oversee the transparency and information dissemination of mutual fund products to investors.

\section{Acknowledgements}

We would like to thank Michael Jantzi for supplying performance data on the Jantzi Social Index. Further data support by Robert Schwob and Style Research Co. Ltd. is gratefully acknowledged. We appreciate the valuable comments of an anonymous referee, Brent Sutton and Kees Koedijk. All remaining errors are the sole responsibility of the authors. The views expressed in this paper are not necessarily shared by ABP Investments.

\section{Notes}

1 See for instance the evidence on investing in socalled "Vice"sectors (gambling, tobacco etc.) in Luck and Tigrani (1994) and Ali and Gold (2002).

2 Studies for the United States include Hamilton et al. (1993), Statman (2000) and Goldreyer et al. (1999), amongst others. Evidence from the United Kingdom includes Luther et al. (1992), Luther and Matatko (1994), Mallin et al. (1995) and Gregory et al. (1997). Australian evidence has been documented by Cummings (2000), Tippit (2001) and Bauer et al. (2006).

3 SIO's report, entitled "Canadian Social Investment Review 2000. A comprehensive survey of socially responsible investment in Canada", can be downloaded from the SIO website: http://www.socialinvestment.ca

4 We also obtained an alternative data set from Fundata Canada Inc, which included unadjusted Net Asset Values: although the overall mean fund returns were biased downwards since distributions were not corrected for, results were very similar and would not affect any of the conclusions in this paper.

5 For example, in a study on conventional Canadian mutual fund performance, Athanassakos et al. (2002) find that excluding dead funds from the sample potentially biases results on fund performance upwards.

6 Information regarding the index construction methodology and the list of companies included can be found at the official website: http://www.mjra-jsi.com

7 We additionally repeated our analyses using returns on S\&P/TSX Composite Index which yielded similar results. 
8 For more on Canadian mutual fund expense ratios, see Ruckman (2003).

\section{References}

Ali P. and M. Gold: 2002, 'Analysing the Cost of Ethical Investments', JASSA 9-14.

Asmundson, P. and S. R. Foerster: 2001, 'Socially Responsible Investing: Better for Your Soul or Your Bottom Line?', Canadian Investment Review.

Athanassakos, G., P. Carayannopolous and M. Racine: 2002, 'How Effective is Aggressive Portfolio Management? Mutual Fund Performance in Canada, 19851996', Canadian Investment Review (Fall) 39-49.

Bauer, R., K. Koedijk and R. Otten: 2005, 'International Evidence on Ethical Mutual Fund Performance and Investment Style', Journal of Banking and Finance 29, 1751-1767.

Bauer, R., R. Otten and A. Tourani Rad: 2006, 'Ethical Investing in Australia, is there a Financial Penalty?', Pacific-Basin Finance Journal 14(1), 33-48.

Berkowitz, M. K. and J. Qiu: 2001, 'Common Risk Factors in Explaining Canadian Equity Returns', Working Paper, University of Toronto.

Berkowitz, M. K. and J. Qiu: 2003, 'Ownership, Risk and Performance of Mutual Fund Management Companies', Journal of Economics and Business 55(2), 109-134.

Carhart, M. M.: 1997, 'On the Persistence in Mutual Fund Performance', Journal of Finance 52(1), 57-82.

Chen, Z. and P. J. Knez: 1996, 'Portfolio Performance Measurement: Theory and Applications', Review of Financial Studies 9(2), 511-556.

Chen, N., R. Roll and S. A. Ross: 1986, 'Economic Forces and the Stock Market', Journal of Business 59(3), 383-403.

Cummings, L.: 2000, 'The Financial Performance of Ethical Investment Trusts: An Australian Perspective', Journal of Business Ethics 25, 79-92.

diBartolomeo, D. and L. Kurtz: 1999, 'Managing Risk Exposures of Socially Screened Portfolios', Research Paper, Northfield Information Services.

Fama, E. and K. R. French: 1992, 'The Cross-Section of Expected Stock Returns', Journal of Finance 47, 427465.

Fama, E. and K. R. French: 1993, 'Common Risk Factors in the Returns on Stocks and Bonds', Journal of Financial Economics 33, 3-53.

Fama, E. and K. R. French: 1996, 'Multifactor Explanations of Asset Pricing Anomalies', Journal of Finance 51, 55-84.
Ferson, W. E. and R. W. Schadt: 1996, 'Measuring Fund Strategy and Performance in Changing Economic Conditions', Journal of Finance 51(2), 425-461.

Goldreyer, E. F., P. Ahmed and J. D. Diltz: 1999, 'The Performance of Socially Responsible Mutual Funds: Incorporating Sociopolitical Information in Portfolio Selection', Managerial Finance 25(1), 23-36.

Gregory, A., J. Matatko and R. Luther: 1997, 'Ethical Unit Trust Financial Performance: Small Company Effects and Fund Size Effects', Journal of Business Finance E Accounting 24(5), 705-725.

Haigh, M. and J. Hazelton: 2004, 'Financial Markets: A Tool for Social Responsibility?', Journal of Business Ethics 52(1), 59-71.

Hamilton, S., H. Jo and M. Statman: 1993, 'Doing Well While Doing Good? The Investment Performance of Socially Responsible Mutual Funds', Financial Analysts Journal 49(6), 62-66.

Jegadeesh, N. and S. Titman: 1993, 'Returns to Buying Winners and Selling Losers: Implications for Stock Market Efficiency', Journal of Finance 48(1), 6591.

L'Her, J.-F., T. Masmoudi and J.-M. Suret: 2001, 'Evidence to support the four-factor pricing model from the Canadian stock market', Journal of International Financial Markets, Institutions and Money 14(4), 313-328.

Luck, C. and V. Tigrani: 1994, 'Ethical Investing and the Returns to Sinful Industries', BARRA Newsletter, Spring.

Luther, R. G., J. Matatko and D. Corner: 1992, 'The Investment Performance of UK Ethical Unit Trusts', Accounting, Auditing and Accountability Journal 5(4), 57-70.

Luther, R. G. and J. Matatko: 1994, 'The Performance of Ethical Unit Trusts: Choosing an Appropriate Benchmark', British Accounting Review 26(1), 7789.

Mallin, C. A., B. Saadouni and R. J. Briston: 1995, 'The Financial Performance of Ethical Investment Funds', Journal of Business Finance \& Accounting 22(4), 483496.

Newey, W. K. and K. D. West: 1987, 'A Simple, Positive Semi-Definite Heteroskedatiscity and Autocorrelation Consistent Variance Covariance Matrix', Econometrica 55(3), 703-708.

Pesaran, M. and A. Timmermann: 1995, 'Predictability of Stock Returns: Robustness and Economic Significance', Journal of Finance 50(4), 1201-1228.

Ruckman, K.: 2003, 'Expense Ratios of North American Mutual Funds', Canadian Journal of Economics 36(1), 192-223. 
Social Investment Organization: 2000, 'Canadian Social Investment Review 2000: A Comprehensive Survey of Socially Responsible Investment in Canada', http:// www.socialinvestment.ca.

Statman, M.: 2000, 'Socially Responsible Mutual Funds', Financial Analysts Journal 57(5-6), 30-39.

Tippet, J.: 2001, 'Performance of Australia's Ethical Funds', The Australian Economic Review 34(2), 170-178.

Rob Bauer and Rogér Otten Department of Finance, Maastricht University, Maastricht, The Netherlands E-mail:R.bauer@finance.unimaas.nl E-mail:R.otten@finance.unimaas.nl

Jeroen Derwall Maastricht University, Maastricht, The Netherlands
Jeroen Derwall

RSM Erasmus University, Burgemeester Oudlaan 50, P.O. Box 1738, 3000, DR, Rotterdam, The Netherlands

E-mail: jderwall@rsm.nl

Rob Bauer ABP Investments, Heerlen, The Netherlands E-mail:r.bauer@finance.unimaas.nl

Rob Bauer and Jeroen Derwall European Centre for Corporate Engagement, Maastricht, The Netherlands 